\title{
openheart Beneficial and harmful effects of sacubitril/valsartan in patients with heart failure: a systematic review of randomised clinical trials with meta-analysis and trial sequential analysis
}

Emil Eik Nielsen (D) , ,2 Joshua Buron Feinberg, ${ }^{1,2}$ Fan-Long Bu, ${ }^{3}$ Michael Hecht Olsen, ${ }^{1,2,4}$ Ilan Raymond, ${ }^{1}$ Frank Steensgaard-Hansen, ${ }^{1}$ Janus Christian Jakobsen ${ }^{2,5}$

\begin{abstract}
- Additional material is published online only. To view, please visit the journal online (http://dx.doi.org/10.1136/ openhrt-2020-001294).
\end{abstract}

To cite: Nielsen EE, Feinberg JB, Bu F-L, et al. Beneficial and harmful effects of sacubitril/ valsartan in patients with heart failure: a systematic review of randomised clinical trials with meta-analysis and trial sequential analysis. Open Heart 2020;7:e001294. doi:10.1136/ openhrt-2020-001294

Received 30 March 2020 Revised 10 September 2020 Accepted 26 October 2020
Check for updates

(C) Author(s) (or their employer(s)) 2020. Re-use permitted under CC BY-NC. No commercial re-use. See rights and permissions. Published by BMJ.

For numbered affiliations see end of article.

Correspondence to Dr Emil Eik Nielsen; Emil.eik. nielsen@gmail.com

\section{ABSTRACT}

Current guidelines recommend angiotensin receptor blocker neprilysin inhibitors (ARNI) (sacubitril/valsartan) as a replacement for angiotensin-converting-enzymeinhibitor (ACE-I) in heart failure with reduced ejection fraction (HFrEF) who remain symptomatic despite optimal medical therapy. The effects of ARNIs have not previously been assessed in a systematic review. We searched for relevant trials until October 2019 in CENTRAL, MEDLINE, Embase, LILACS, BIOSIS, CNKI, VIP, WanFang and CBM. Our primary outcomes were all-cause mortality and serious adverse events. We systematically assessed the risks of random errors and systematic errors. PROSPERO registration: CRD42019129336. 48 trials randomising 19 086 participants were included. The ARNI assessed in all trials was sacubitril/valsartan. ACE-I or ARB were used as control interventions. Trials randomising HFrEF participants (27 trials) and heart failure with preserved ejection fraction (HFpEF) participants (four trials) were analysed separately. In HFrEF participants, meta-analyses and Trial Sequential Analyses showed evidence of a beneficial effect of sacubitril/ valsartan when assessing all-cause mortality (risk ratio (RR), $0.86 ; 95 \% \mathrm{Cl}, 0.79$ to 0.94 ) and serious adverse events (RR, $0.89 ; 95 \% \mathrm{Cl}, 0.86$ to 0.93 ); and the results did not differ between the guideline recommended target population and HFrEF participants in general. We found no evidence of an effect of sacubitril/valsartan in HFpEF participants. Sacubitril/ valsartan compared with either ACE-I or ARB seems to have a beneficial effect in patients with HFrEF. Our results indicate that sacubitril/valsartan might be beneficial in a wider population of patients with heart failure than the guideline recommended target population. Sacubitril/valsartan does not seem to show evidence of a difference compared with valsartan in patients with HFpEF.

\section{INTRODUCTION}

Worldwide, an estimated 37 million people have a diagnosis of heart failure. ${ }^{2}$ The lifetime risk for developing heart failure is approximately $20 \% .^{3}$ The prevalence of heart

\section{Key questions}

What is already known about this subject?

- Sacubitril/valsartan is recommended as an alternative to angiotensin-converting-enzyme inhibitor in patients with heart failure with reduced ejection fraction who remain symptomatic despite optimal medical therapy.

- No former systematic review has been conducted.

What does this study add?

- Meta-analysis and Trial Sequential Analyses shows that sacubitril/valsartan reduces the risk of allcause mortality, serious adverse events, hospitalisations and NT-proBNP as well as increases quality of life and ejection fraction.

How might this impact on clinical practice?

- Our results indicate that sacubitril/valsartan might be beneficial in a wider population of patients with heart failure with reduced ejection fraction.

failure is increasing, presumably caused by an increase in both life expectancy and risk factors leading to heart failure as well as improved treatment of acute cardiovascular events. 1245

Guidelines recommend treatment of heart failure with reduced ejection fraction with a beta-blocker and an inhibitor of the reninangiotensin-aldosterone system (angiotensinconverting-enzyme inhibitor (ACE-I) or angiotensin II receptor blocker (ARB)). It is recommended to add a mineralocorticoidreceptor antagonist in patients who remain symptomatic after this initial treatment. ${ }^{36}$

New drugs for heart failure have been developed and approved that combine inhibition of the renin-angiotensin-aldosterone system pathway (with an $\mathrm{ARB}$ ) with inhibition of the 
neprilysin enzyme. These new types of drugs are classified as angiotensin receptor blocker neprilysin inhibitors (ARNIs). ${ }^{7}$

The European Society of Cardiology recommends ARNIs as a replacement for ACE-I in patients with heart failure with reduced ejection fraction (HFrEF) (EF $<35 \%$ ) who remain symptomatic (New York Heart Association (NYHA) II to IV) despite optimal medical therapy with an ACE-I, a beta-blocker and a mineralocorticoidreceptor antagonist (unless there are contraindications) ${ }^{6}$ The American College of Cardiology/American Heart Association Task Force on Clinical Practice Guidelines and the Heart Failure Society of America, make similar recommendations. ${ }^{8}$

To our knowledge, the effects of ARNIs have not been assessed previously in a systematic review. ${ }^{9}$

\section{METHODS}

This systematic review has been developed based on the Preferred Reporting Items for Systematic Reviews and Meta-Analysis Protocols (PRISMA-P) guidelines for reporting systematic reviews evaluating interventions in healthcare (online supplemental S1 text). ${ }^{910}$ Our methodology was predefined and described in detail in our pre-published protocol. ${ }^{11}$

In short, we included all trials assessing the beneficial and harmful effects of ARNIs in participants with any type of heart failure. ${ }^{11}$ We included randomised clinical trials irrespective of trial design, setting, publication status, publication year and language. We searched from their inception to October 2019 for relevant trials in the Cochrane Central Register of Controlled Trials (CENTRAL), Medical Literature Analysis and Retrieval System Online (MEDLINE), Excerpta Medica database (Embase), Latin American and Caribbean Health Sciences Literature (LILACS), Science Citation Index Expanded on Web of Science, Chinese Biomedical Literature Database (CBM), China National Knowledge Infrastructure (CNKI), Chinese Science Journal Database (VIP), WanFang, SINOMED and BIOSIS. The search strategy can be found in (online supplemental S2 text). Additionally, we hand searched reference lists, major pharmaceutical companies and several databases for relevant publications.

\section{Outcomes and subgroup analyses}

Our primary outcomes were all-cause mortality, serious adverse events; secondary outcomes were myocardial infarction, quality of life, non-serious adverse events and hospitalisations; and exploratory outcomes were cardiovascular mortality, ejection fraction, 6-min walking distance, and NT-proBNP. We used the trial results reported at maximum follow-up. ${ }^{11}$ We planned several subgroup analyses (test of interaction) ${ }^{12}$ and sensitivity analyses ${ }^{11}$ (see 'Results'). In addition we added three subgroup analyses: (1) trials comparing different co-interventions, (2) trials published in English compared with Chinese and (3) trials using guideline criteria for inclusion compared with trials with broader inclusion criteria.

\section{Data collection and risk of bias}

Three authors (EEN, JF and F-LB) extracted data and assessed risks of bias of the included trials using standardised extraction sheets. Disagreements were resolved by discussion with a third author (JCJ). Our bias risk assessment was based on the results of meta-epidemiological studies (online supplemental S2 ref). Hence, risks of bias were assessed using the domains random sequence generation, allocation concealment, blinding of participants and treatment providers, blinding of outcome assessment, incomplete outcome data, selective outcome reporting, for profit bias and other risks of bias. ${ }^{13}$ We contacted all authors by email in order to retrieve missing information.

\section{Data synthesis and assessment of significance}

We used the statistical software Review Manager 5.3 provided by Cochrane to analyse data. ${ }^{12}$ We assessed our intervention effects with both random-effects metaanalyses $^{15}$ and fixed-effect meta-analyses. ${ }^{16}$ We primarily used the most conservative point estimate of the two. ${ }^{17}$ We assessed two primary outcomes, and therefore, we considered a p value of 0.033 as the threshold for statistical significance. ${ }^{17}$ We investigated possible heterogeneity through subgroup analyses (test of interaction). ${ }^{12}$ In order to control the risks of type I errors and type II errors, we performed Trial Sequential Analysis. ${ }^{17}$

\section{RESULTS \\ Study characteristics}

We identified 2393 potentially relevant studies through our literature search conducted in October 2019. In addition, three potential studies were identified through Novartis clinical registry. We included a total of 48 trials randomising 19086 participants (figure 1). In all trials, the experimental intervention was $97 \mathrm{mg}$ sacubitril/ $103 \mathrm{mg}$ valsartan two times per day. The trials were conducted between 2012 and 2019 in 48 different countries. Nine of the included trials were written in English and published in Western databases and these trials accounted for $83 \%$ of the included participants. Two of these trials randomised $71 \%$ of all participants. ${ }^{1819}$ Thirty-nine trials were conducted and published in China. These trials were generally small (34 to 180 participants) and reported mostly on surrogate outcomes (left ventricular ejection fraction, 6-min walking distance and NT-proBNP). Characteristics of included studies are summarised in (table 1).

All nine trials published in English-language journals were judged to be high risk of bias mainly due to industry funding; Novartis Pharmaceuticals funded all nine trials. All trials published in Chinese were judged to be of high risk of bias and of low methodological quality; for example, none of the trials registered/ published protocols, used blinding and only 18/39 reported how the randomisation process was conducted (figure 2).

Twenty-seven trials randomised a total of $12311 \mathrm{HFrEF}$ participants and four trials randomised 5278 heart failure 


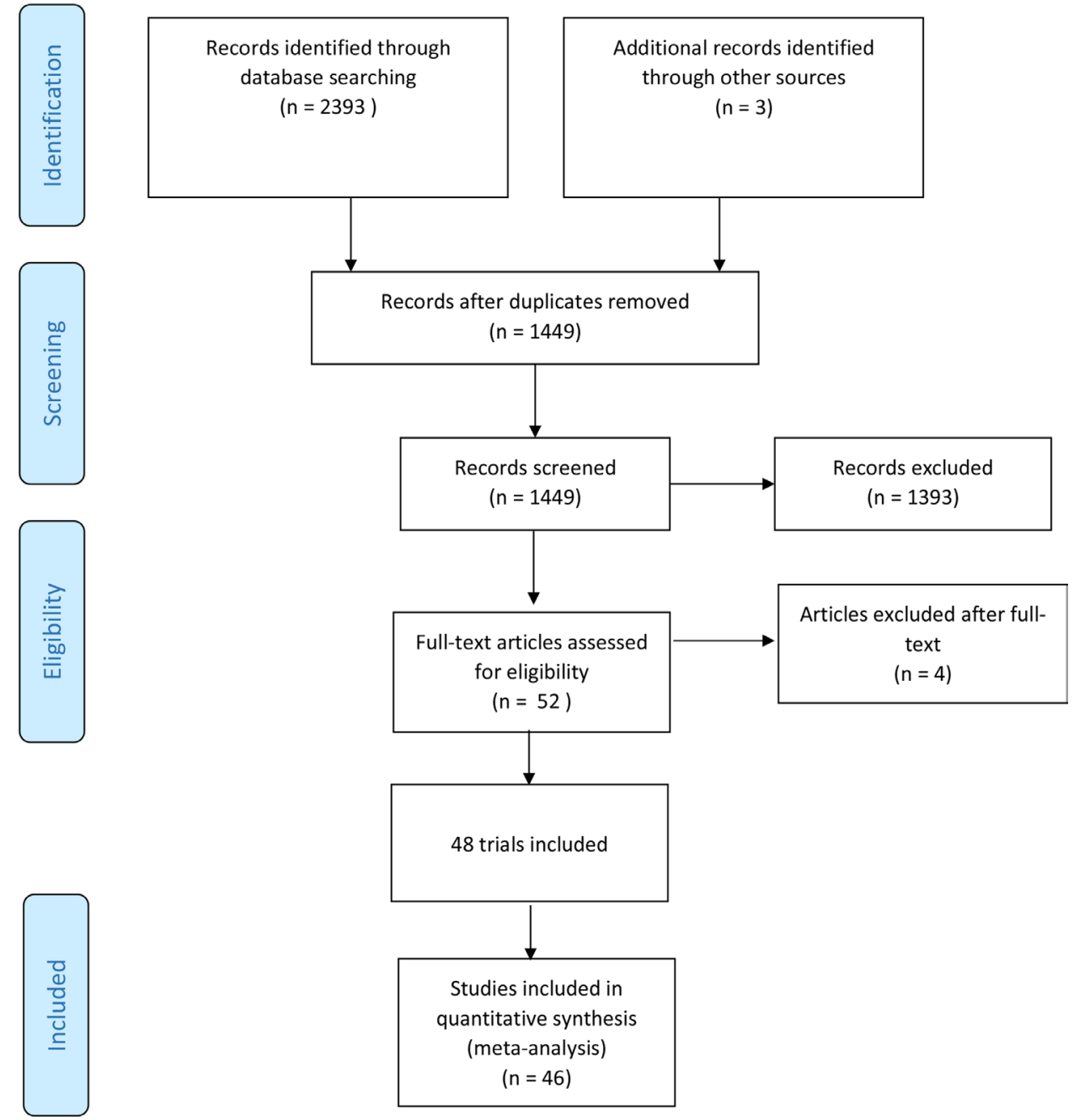

Figure 1 PRISMA (Preferred Reporting Items for Systematic Reviews and Meta-Analysis) flow diagram.

with preserved ejection fraction (HFpEF) participants. The remaining 17 trials randomising a total of 1497 participants either did not specify which type of heart failure they assessed, or they included participants with different types of heart failure. The majority $(93.0 \%)$ of the total number of randomised participants had NYHA II or III. The mean age of the trial participants was 65.9 years and the mean proportion of women was $34.2 \%$. Baseline characteristics are summarised in (table 2).

The trials used different control interventions: 14 trials used valsartan, 20 trials used an ACE-I (enalapril=12, benazepril $=7$, perindopril $=1$ and ramipril $=1) ; 8$ trials did not administer any comparator to the control group besides usual care, which was planned to be administered in both groups (as co-intervention); and 4 trials used either an unspecified ARB or an unspecified ACE-I. One trial used intravenous milrinone as control intervention. All trials used guideline recommended co-interventions (usual care) planned to be delivered similarly in both intervention groups, that is, beta-blockers, mineralocorticoid-receptor antagonists, diuretics and digitalis, if indicated.

Visual inspection of the forest plots and statistical tests $\left(\mathrm{I}^{2}\right.$ statistics) showed signs of heterogeneity (figure 3 and online supplemental S1 figure). When trials randomising
HFrEF participants and trials randomising HFpEF participants were analysed separately, then the heterogeneity was mostly resolved. Hence, we chose to report results separately for each type of heart failure. ${ }^{11}$

\section{Participants with heart failure with reduced ejection fraction Primary outcomes All-cause mortality}

Seven trials randomising a total of $10794 \mathrm{HFrEF}$ participants reported on all-cause mortality. A total of 745/5382 (13.8\%) sacubitril/valsartan participants died compared with 874/5412 (16.1\%) control participants (mean follow-up of 22.8 months). Meta-analysis (risk ratio (RR), $0.86 ; 95 \% \mathrm{CI}, 0.79$ to $0.94 ; \mathrm{p}=0.0008$ ) showed evidence of a beneficial effect of sacubitril/valsartan compared with control (figure 4). Neither visual inspection of the forest plot nor tests for statistical heterogeneity $\left(\mathrm{I}^{2}=0 \% ; \mathrm{p}=0.84\right)$ indicated significant heterogeneity. Trial Sequential Analysis showed that there was enough information to confirm that sacubitril/valsartan compared with control reduced the risk of death by $15 \%$ (figure 5 ). Incomplete outcome data alone did not seem to have the potential to influence the meta-analysis results (online supplemental S2 and S3 figures). The following tests of interaction 
Table 1 Characteristics of included studies

\begin{tabular}{|c|c|c|c|c|c|c|c|}
\hline Study (year) & Region & $\begin{array}{l}\text { Type of heart } \\
\text { failure }\end{array}$ & $\begin{array}{l}\text { Chronic/ } \\
\text { acute }\end{array}$ & Control intervention & Dates & $\begin{array}{l}\text { Number of } \\
\text { participants }\end{array}$ & $\begin{array}{l}\text { Maximum follow-up } \\
\text { (months) }\end{array}$ \\
\hline $\begin{array}{l}\text { AWAKE-HF et al } \\
(2019)^{30}\end{array}$ & English & HFrEF & Chronic & Enalapril & 2016-2018 & 70 & 4 \\
\hline $\begin{array}{l}\text { CLCZ696B2223 et al } \\
(2013)^{31}\end{array}$ & English & HFrEF & Chronic & Valsartan & 2011-2012 & 8 & 0.23 \\
\hline $\begin{array}{l}\text { EVALUATE-HF } \\
\text { et al }(2019)^{32}\end{array}$ & English & HFrEF & Chronic & Enalapril & 2016-2018 & 232 & 2.75 \\
\hline PARADIGM-HF et al (2014 ${ }^{19}$ & English & HFrEF & Chronic & Enalapril & 2009-2012 & 4209 & 27 \\
\hline $\begin{array}{l}\text { PARAGON-HF et al } \\
(2019)^{18}\end{array}$ & English & HFpEF & Chronic & Valsartan & 2014-2016 & 2419 & 35 \\
\hline $\begin{array}{l}\text { PARAMOUNT et al } \\
(2012)^{22}\end{array}$ & English & HFpEF & Chronic & Valsartan & 2009-2011 & 149 & 21 \\
\hline $\begin{array}{l}\text { PRIME-HF et al } \\
(2019)^{35}\end{array}$ & English & HFrEF & Chronic & Valsartan & 2016-2017 & 60 & 12 \\
\hline $\begin{array}{l}\text { Chai DJ et al } \\
(2019)^{36}\end{array}$ & Chinese & HFrEF & Chronic & Milinon & 2017-2018 & 48 & 0.01 (72 hours) \\
\hline $\begin{array}{l}\text { Chen CW et al } \\
(2019)^{37}\end{array}$ & Chinese & Unclear & Chronic & Enalapril & 2018-2019 & 40 & 1 \\
\hline $\begin{array}{l}\text { Chen L et al } \\
(2019)^{38}\end{array}$ & Chinese & HFrEF & Unclear & Enalapril & 2017-2018 & 32 & 6 \\
\hline $\begin{array}{l}\text { Dai WL et al } \\
(2019)^{39}\end{array}$ & Chinese & HFrEF & Chronic & Ramipril & 2017-2019 & 98 & 6 \\
\hline $\begin{array}{l}\text { Dong L et al } \\
(2019)^{40}\end{array}$ & Chinese & HFrEF & Chronic & Valsartan & 2017-2018 & 30 & 2.75 \\
\hline $\begin{array}{l}\text { Gao Y et al } \\
(2019)^{44}\end{array}$ & Chinese & HFrEF & Chronic & Valsartan & 2017-2018 & 17 & 1.75 \\
\hline $\begin{array}{l}\text { Han ZQ et al } \\
(2019)^{23}\end{array}$ & Chinese & HFpEF & Unclear & Valsartan & 2016-2018 & 39 & 2.25 \\
\hline $\begin{array}{l}\text { Hao QM et al } \\
(2019)^{45}\end{array}$ & Chinese & HFrEF & Chronic & Valsartan & 2017-2018 & 30 & 1.75 \\
\hline $\begin{array}{l}\text { Huang SB et al } \\
(2019)^{46}\end{array}$ & Chinese & HFpEF & Chronic & Usual care & 2017-2018 & 39 & 6 \\
\hline $\begin{array}{l}\text { Ke ZF et al } \\
(2019)^{47}\end{array}$ & Chinese & HFrEF & Chronic & Usual care & 2017-2018 & 35 & 3 \\
\hline $\begin{array}{l}\text { Li GX et al } \\
(2019)^{48}\end{array}$ & Chinese & Unclear & Chronic & Benazepril & 2017-2018 & 27 & 3 \\
\hline $\begin{array}{l}\text { Li J (1) et al } \\
(2019)^{49}\end{array}$ & Chinese & HFrEF & Chronic & Enalapril & 2017-2018 & 47 & 6 \\
\hline $\begin{array}{l}\text { Li J (2) et al } \\
(2019)^{50}\end{array}$ & Chinese & Unclear & Chronic & Benazepril & 2017-2017 & 62 & 12 \\
\hline $\begin{array}{l}\text { Liang HB et al } \\
(2019)^{51}\end{array}$ & Chinese & HFrEF & Unclear & Perindopril & 2018-2019 & 50 & 3 \\
\hline $\begin{array}{l}\text { Liu DN et al } \\
(2019)^{52}\end{array}$ & Chinese & HFrEF & Chronic & Usual care & $2017-2018$ & 48 & NR \\
\hline $\begin{array}{l}\text { Liu YH et al } \\
(2019)^{53}\end{array}$ & Chinese & HFrEF & Chronic & Benazepril/candesartan & 2017-2018 & 26 & 6 \\
\hline
\end{tabular}




\begin{tabular}{|c|c|c|c|c|c|c|c|}
\hline Study (year) & Region & $\begin{array}{l}\text { Type of heart } \\
\text { failure }\end{array}$ & $\begin{array}{l}\text { Chronic/ } \\
\text { acute }\end{array}$ & Control intervention & Dates & $\begin{array}{l}\text { Number of } \\
\text { participants }\end{array}$ & $\begin{array}{l}\text { Maximum follow-up } \\
\text { (months) }\end{array}$ \\
\hline $\begin{array}{l}\text { Shen JH et al } \\
(2019)^{55}\end{array}$ & Chinese & Unclear & Chronic & Valsartan & 2017-2018 & 51 & 3 \\
\hline $\begin{array}{l}\text { Sun X et al } \\
(2019)^{57}\end{array}$ & Chinese & Unclear & Chronic & Usual care & 2017-2018 & 36 & 1 \\
\hline $\begin{array}{l}\text { Sun XN et al } \\
(2018)^{58}\end{array}$ & Chinese & Unclear & Chronic & Enalapril & 2017-2018 & 58 & 3 \\
\hline $\begin{array}{l}\text { Tang J et al } \\
(2018)^{59}\end{array}$ & Chinese & Unclear & Chronic & Bisoprolol & 2017-2018 & 50 & 1 \\
\hline $\begin{array}{l}\text { Wei ZX et al } \\
(2019)^{61}\end{array}$ & Chinese & HFrEF & Unclear & Valsartan & 2017-2018 & 30 & 3 \\
\hline $\begin{array}{l}\text { Wu MM et al } \\
(2018)^{62}\end{array}$ & Chinese & HFrEF & Chronic & Benazepril & 2017-2018 & 20 & 1 \\
\hline $\begin{array}{l}\text { Yang J et al } \\
(2019)^{63}\end{array}$ & Chinese & Unclear & Chronic & Benazepril & 2016-2018 & 46 & 3 \\
\hline $\begin{array}{l}\text { Yang RC et al } \\
(2018)^{64}\end{array}$ & Chinese & Unclear & Chronic & Valsartan & 2017-2018 & 57 & 2 \\
\hline $\begin{array}{l}\text { Yao LN et al } \\
(2019)^{65}\end{array}$ & Chinese & HFrEF & Chronic & ACE-I/ARB & 2018-2019 & 27 & NR \\
\hline $\begin{array}{l}\text { Yu H et al } \\
(2019)^{66}\end{array}$ & Chinese & $\begin{array}{l}\text { HFrEF and } \\
\text { HFmrEF }\end{array}$ & Chronic & Valsartan & 2018-2019 & 40 & 2.75 \\
\hline $\begin{array}{l}\text { Zhang XJ et al } \\
(2019)^{70}\end{array}$ & Chinese & Unclear & Chronic & Benazepril & 2017-2017 & 40 & 2.25 \\
\hline $\begin{array}{l}\text { Zhang Y et al } \\
(2019)^{71}\end{array}$ & Chinese & HFrEF & Chronic & Valsartan & 2017-2018 & 28 & 3 \\
\hline $\begin{array}{l}\text { Zhang YZ et al } \\
(2019)^{72}\end{array}$ & Chinese & HFrEF & Chronic & Benazepril & 2017-2018 & 40 & 3 \\
\hline $\begin{array}{l}\text { Zhao YQ et al } \\
(2019)^{73}\end{array}$ & Chinese & Unclear & Unclear & Usual care & 2016-2017 & 85 & 12 \\
\hline
\end{tabular}

ACE-I, angiotensin-converting-enzyme inhibitor; ARB, angiotensin II receptor blocker; HFmrEF, heart failure with midrange ejection fraction; HFpEF, heart failure with preserved ejection fraction; HFrEF, heart failure with reduced ejection fraction.

showed no evidence of a difference: (1) acute decompensated heart failure participants compared with chronic heart failure participants $(\mathrm{p}=0.53)$; (2) different types of control intervention (valsartan, enalapril and benazepril) $(\mathrm{p}=0.68)$; (3) trials published in English compared with trials published in Chinese $(\mathrm{p}=0.64)$; and (4) trials using guideline criteria for inclusion compared with trials with broader inclusion criteria $(\mathrm{p}=0.77)$ (online supplemental S4-S7 figures). None of the remaining planned subgroup analyses could be conducted due to lack of relevant data. ${ }^{11}$

\section{Serious adverse events}

Seven trials randomising a total of $10794 \mathrm{HFrEF}$ participants reported on serious adverse events. A total of 2013/5382 (37.4\%) sacubitril/valsartan participants had a serious adverse event compared with 2263/5412 (41.8\%) control participants (mean follow-up of 22.8 months). Meta-analysis (RR, $0.89 ; 95 \%$ CI, 0.86 to $0.94 ; \mathrm{p}=<0.00001$ ) showed evidence of a beneficial effect of sacubitril/ valsartan compared with control (figure 6). Neither visual inspection of the forest plot nor test for statistical heterogeneity $\left(I^{2}=33 \% ; p=0.17\right)$ indicated significant heterogeneity. 


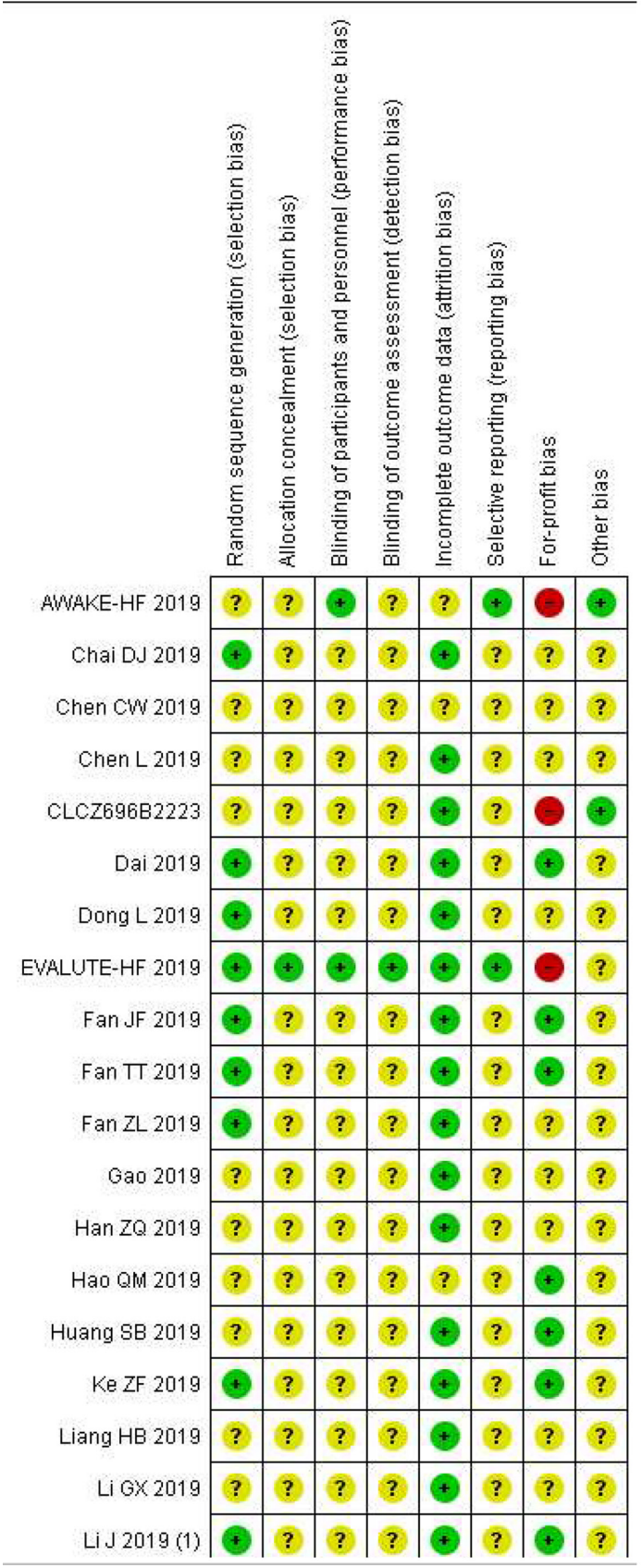

Figure 2 Risk of bias summary.

Trial Sequential Analysis showed that there was enough information to confirm that sacubitril/valsartan compared with control reduced the risk of serious adverse events by $15 \%$ (figure 7 ). Incomplete outcome data alone did not seem to have the potential to influence the metaanalysis results (online supplemental S8 and S9 figures). The following tests of interaction showed no evidence of a difference: (1) different types of control intervention (valsartan, enalapril and and benazepril) $(\mathrm{p}=0.81)$; (2) trials published in English compared with trials published in Chinese $(p=0.77)$; (3) trials using guideline criteria for inclusion compared with trials with broader inclusion criteria ( $\mathrm{p}=0.62$ ) (online supplemental S10-S12 figures). Test of interaction showed evidence of a difference when comparing acute decompensated heart failure participants

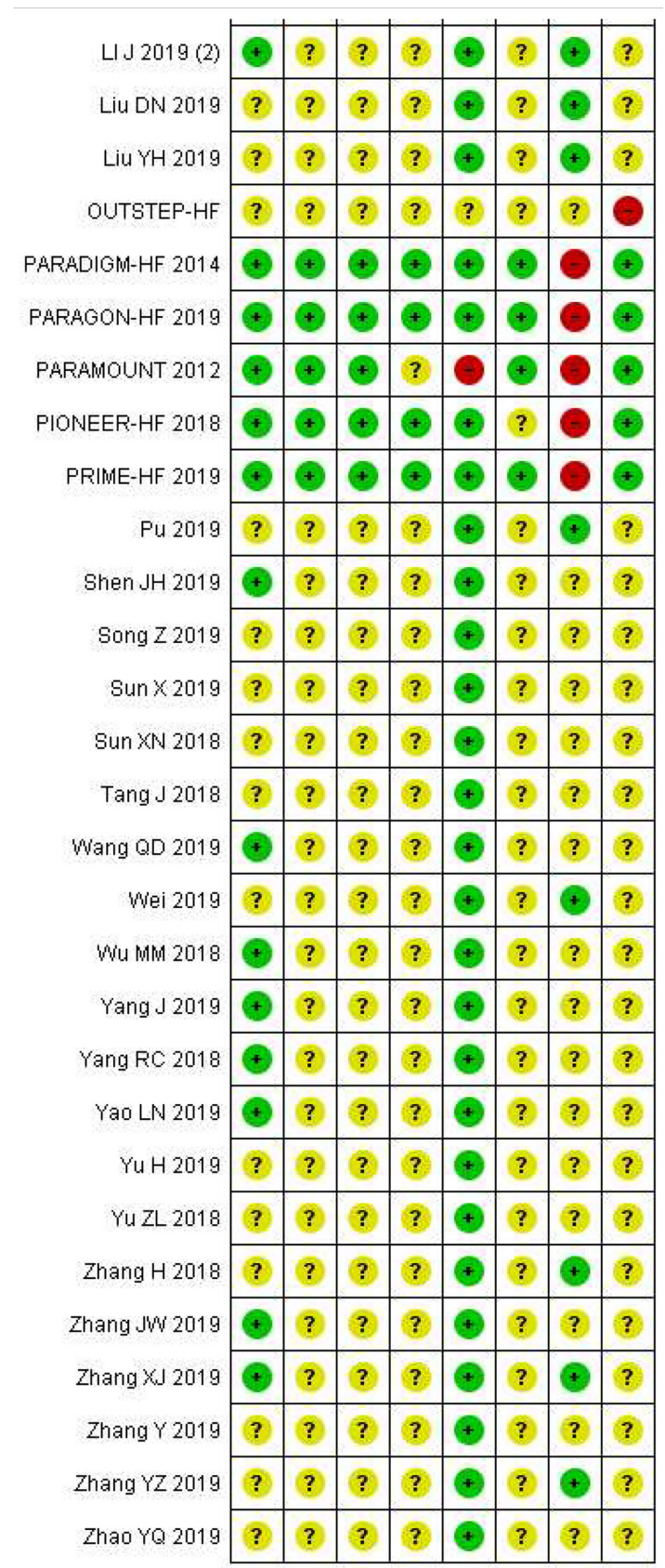

to chronic heart failure participants $(\mathrm{p}=0.004)$ (online supplemental S13 figure). One trial randomised 881 participants with acute decompensated heart failure. However, this trial did not publish a full list of serious adverse events but only reported a predefined composite of serious clinical events. The remaining six trials randomised participants with chronic heart failure. None of the remaining planned subgroup analyses could be conducted due to lack of relevant data. ${ }^{11}$

All serious adverse events were analysed individually and can be found in supplemental appendix (online supplemental S1 table). As a hypothesis generating analyses, we performed meta-analyses on all serious adverse events. Meta-analysis showed evidence of a beneficial effect of sacubitril/valsartan compared with control, when assessing 
Table 2 Baseline characteristics

\begin{tabular}{|c|c|c|c|c|c|}
\hline & $\begin{array}{l}\text { Trials providing } \\
\text { information }\end{array}$ & ARNI & $\begin{array}{l}\text { No. analysed } \\
\text { (ARNI) }\end{array}$ & Control & $\begin{array}{l}\text { No. analysed } \\
\text { (Control) }\end{array}$ \\
\hline Age - years (SD) & 46 & $66.1(9.8)$ & 9433 & $66.0(9.7)$ & 9408 \\
\hline Male sex - n (\%) & 46 & $6214(65.9)$ & 9433 & $6178(66.0))$ & 9358 \\
\hline Female sex - $\mathrm{n}(\%)$ & 46 & $3220(34.1)$ & 9433 & $3194(34.0)$ & 9358 \\
\hline Mean body mass index (SD) & 10 & $29.0(5.3)$ & 7600 & $29.0(5.3)$ & 7611 \\
\hline History of atrial fibrillation - $\mathrm{n}(\%)$ & 6 & $2530(34.7)$ & 7290 & $2610(35.7)$ & 7301 \\
\hline Diabetes - n (\%) & 11 & $2757(36.3)$ & 7578 & $2748(36.2)$ & 7591 \\
\hline Hypertension - n (\%) & 15 & $6024(77.8)$ & 7744 & $5995(77.3)$ & 7751 \\
\hline Previous heart failure - hospitalisation $-\mathrm{n}(\%)$ & 5 & $3960(56.3)$ & 7034 & $4050(57.7)$ & 7044 \\
\hline Previous myocardial infarction - $\mathrm{n}(\%)$ & 6 & $2454(33.7)$ & 7278 & $2417(33.1)$ & 7287 \\
\hline NYHA-class - n (\%) & 26 & & 8735 & & 8335 \\
\hline NYHA 1 & & $291(0.35)$ & & $307(0.37)$ & \\
\hline NYHA 2 & & $5558(66.7)$ & & $5478(65.7)$ & \\
\hline NYHA 3 & & $2205(26.5)$ & & $2289(27.4)$ & \\
\hline NYHA 4 & & $257(3.1)$ & & $256(3.1)$ & \\
\hline Heart failure classification $-\mathrm{n}(\%)$ & 32 & & 8694 & & 8722 \\
\hline Heart failure with reduced ejection fraction & & 6025 & & 6069 & \\
\hline Heart failure with midrange ejection fraction & & 0 & & 0 & \\
\hline Heart failure with preserved ejection fraction & & 2669 & & 2653 & \\
\hline \multicolumn{6}{|l|}{ Baseline medications - $\mathrm{n}(\%)$} \\
\hline Beta-blockers & 10 & $6634(85.8)$ & 7731 & $6608(85.6)$ & 7716 \\
\hline Diuretics & 8 & $6284(82.9)$ & 7583 & $6291(82.5)$ & 7618 \\
\hline MRA & 9 & $3164(41.3)$ & 7654 & $3353(43.7)$ & 7667 \\
\hline Pretrial ACE-I & 3 & $3363(76.5)$ & 4396 & $3361(76.0)$ & 4422 \\
\hline Pretrial ARB & 3 & $1032(23.5)$ & 4396 & $1068(24.2)$ & 4422 \\
\hline Pretrial ARB/ACE-I & 8 & 6936 (91.5) & 7583 & 6988 (92.0) & 7598 \\
\hline
\end{tabular}

ACE-I, angiotensin-converting-enzyme inhibitor; ARB, angiotensin II receptor blocker; ARNI, angiotensin receptor blocker neprilysin inhibitor; MRA, mineralocorticoid-receptor antagonists; NYHA, New York Heart Association.

the risk of hyperkalaemia (RR 0.44; $95 \%$ CI, 0.26 to 0.76 ; $\mathrm{p}=0.003$ ), fatigue (RR $0.10 ; 95 \% \mathrm{CI}, 0.10$ to $0.79 ; \mathrm{p}=0.03$ ) and syncope (RR $0.62 ; 95 \%$ CI, 0.43 to $0.91 ; \mathrm{P} 0.01$ ). Prior neprilysin in combination with ACE-I have shown an elevated risk of angioedema. Meta-analysis showed no evidence of a difference between sacubitril/valsartan compared with control on angioedema (RR 1.01; 95\% CI, 0.27 to $3.72 ; \mathrm{p}=0.99$ ).

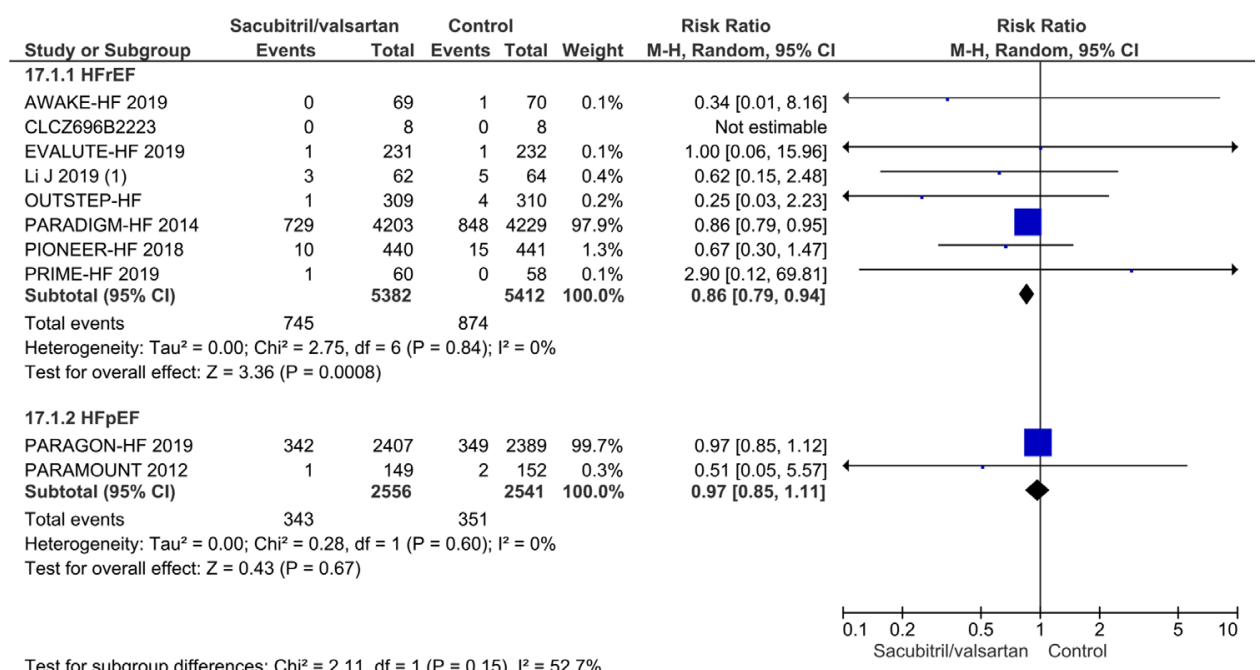

Figure 3 Forest plot of subgroup based on type of heart failure on all-cause mortality. 


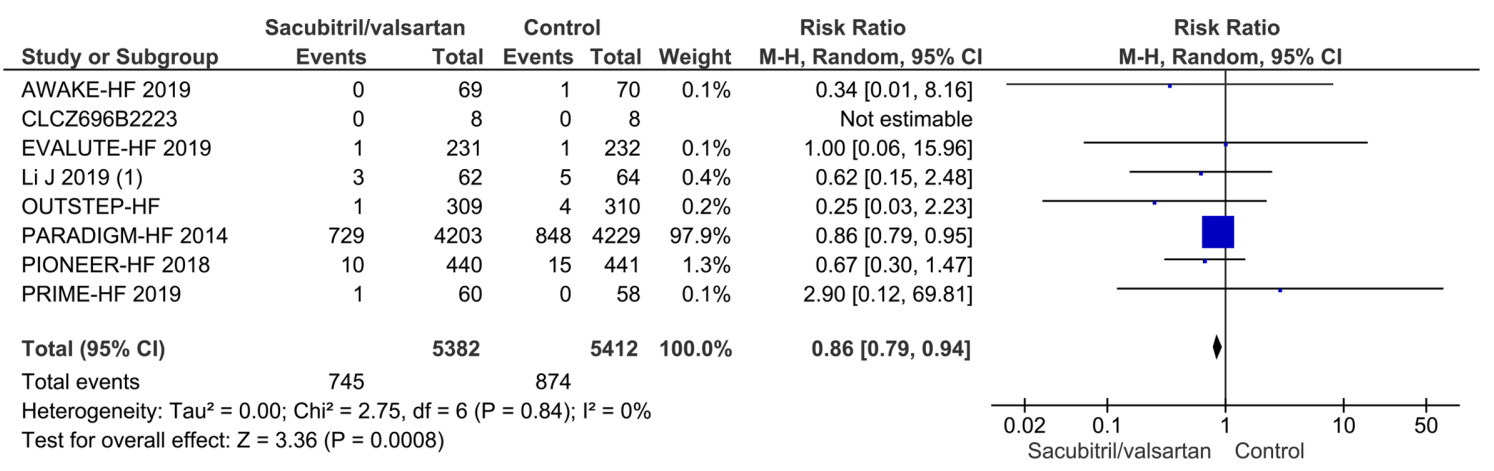

\section{Secondary outcomes}

\section{Myocardial infarction}

Two trials randomising a total of 9051 HFrEF participants reported on myocardial infarction. A total of $70 / 4513$ $(1.6 \%)$ sacubitril/valsartan participants had a myocardial infarction compared with 72/4538 (1.6\%) control participants. Meta-analysis (RR, $0.98 ; 95 \%$ CI, 0.71 to 1.35 ; $\mathrm{p}=0.89$ ) showed no evidence of a difference between sacubitril/ valsartan and control (online supplemental S14 figure). Neither visual inspection of the forest plot nor tests for statistical heterogeneity $\left(\mathrm{I}^{2}=0 \% ; \mathrm{p}=0.62\right)$ indicated significant heterogeneity. Trial Sequential Analysis showed that there was not enough information to confirm or reject that sacubitril/valsartan compared with control reduced the risk of myocardial infarction by $15 \%$ (online supplemental S15 figure). Incomplete outcome data alone did not seem to have the potential to influence the meta-analysis results (online supplemental S16 and S17 figures). None of the planned subgroup analyses could be conducted due to lack of relevant data. ${ }^{11}$

\section{Quality of life}

Two Chinese trials randomising $232 \mathrm{HFrEF}$ participants reported on quality of life using the Minnesota Living with Heart Failure Questionnaire (MLHFQ). Metaanalysis (mean difference (MD), $-5.19 ; 95 \%$ CI, -8.37 to $-2.01 ; \mathrm{p}=0.001$ ) showed evidence of a beneficial effect of sacubitril/valsartan compared with control (online supplemental S18 figure). Both visual inspection of the forest plot and tests for statistical heterogeneity $\left(\mathrm{I}^{2}=85 \%\right.$; $\mathrm{p}=0.01$ ) indicated substantial signs of heterogeneity which could not be resolved. Trial Sequential Analysis showed that there was enough information to confirm a MD of 5 (online supplemental S19 figure). Incomplete outcome data alone did not seem to have the potential to influence the results. Only one trial randomising 8442 participants reported on quality of life using the Kansas

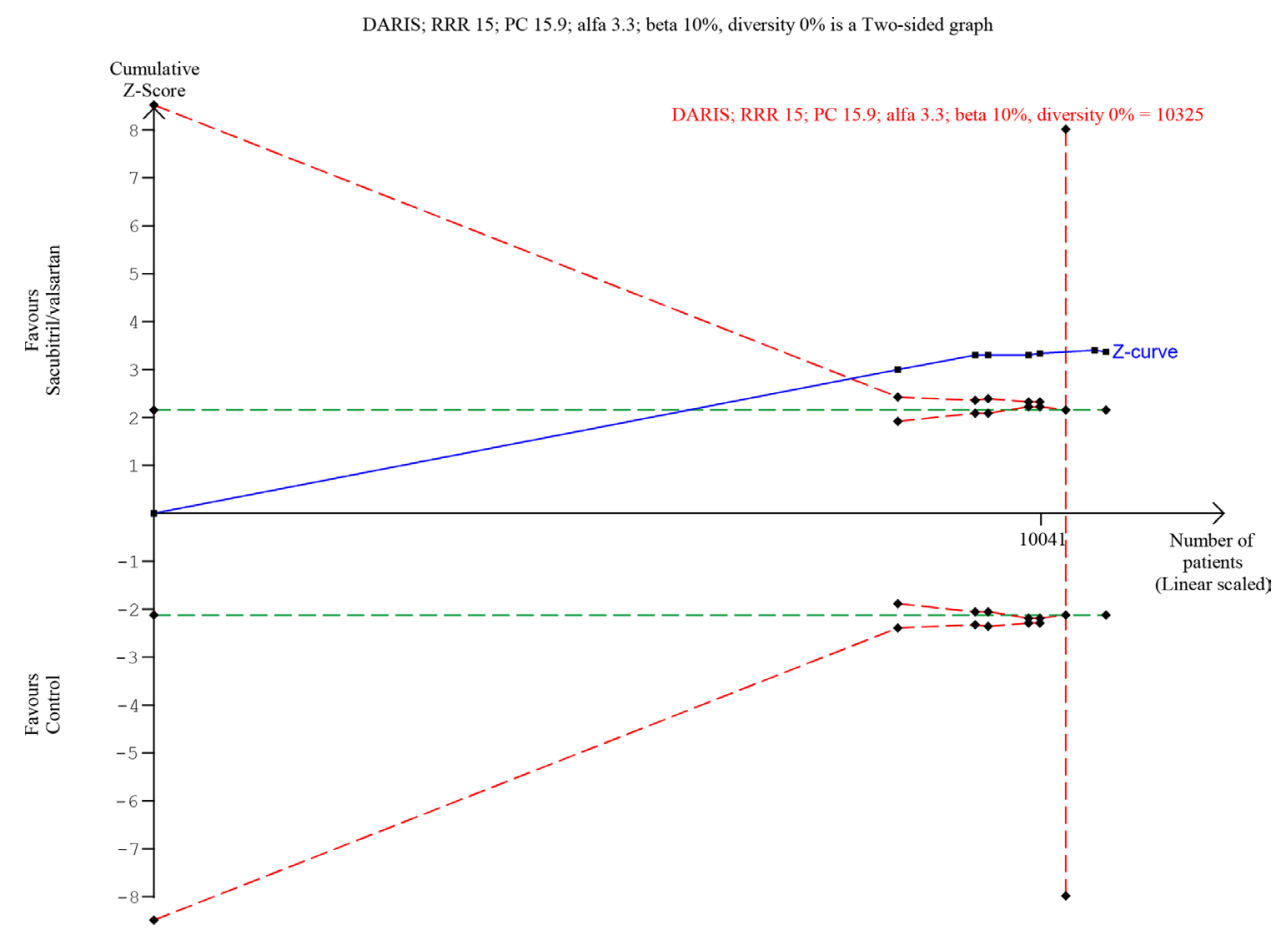

Figure 5 Trial sequential analysis of participants with heart failure with reduced ejection fraction on all-cause mortality. 


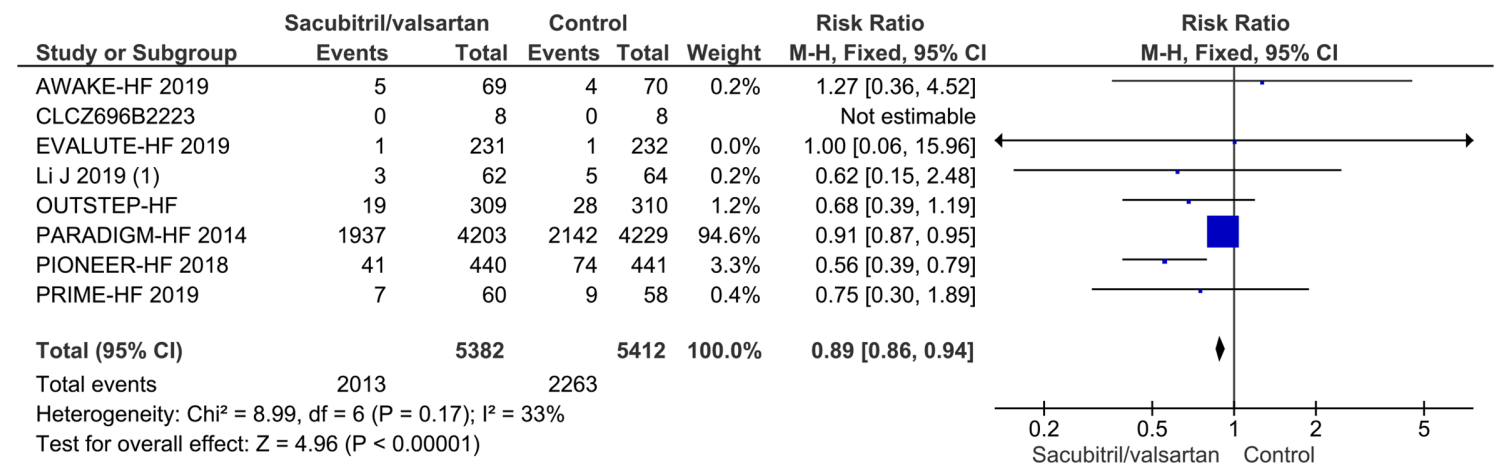

Figure 6 Forest plot of participants with heart failure with reduced ejection fraction on serious adverse events.

City Cardiomyopathy Questionnaire (KCCQ). ${ }^{20}$ The trial had a follow-up of 36 months and found a least squared mean of $2.28(0.73)$, with a $p$ value of 0.002 . None of the planned subgroup analyses could be conducted due to lack of relevant data.

\section{Non-serious adverse events}

Nine trials randomising a total of $10401 \mathrm{HFrEF}$ participants reported on non-serious adverse events. A total of 2738/5186 (52.8\%) sacubitril/valsartan participants had a non-serious adverse event compared with $2855 / 5215$ (54.7\%) control participants. Meta-analysis (RR, 0.91; $95 \%$ CI, 0.74 to $1.11 ; \mathrm{p}=0.35$ ) showed no evidence of a difference between sacubitril/valsartan and control (online supplemental S20 figure). Both visual inspection of the forest plot and tests for statistical heterogeneity $\left(\mathrm{I}^{2}=60 \%\right.$; $\mathrm{p}=0.009$ ) indicated moderate signs of heterogeneity which could not be resolved. Trial Sequential Analysis showed that there was not enough information to confirm or reject that sacubitril/valsartan compared with control reduced the risk of non-serious adverse events by $15 \%$ (online supplemental S21 figure). Incomplete outcome data alone did not have the potential to influence the meta-analysis results (online supplemental S22 and S23 figures). Test of interaction showed evidence of a difference when comparing trials only including patients according to current guidelines compared with trials including all HFrEF participants (online supplemental S24 figure). Three subgroup analyses showed no evidence of a difference (online supplemental figures 25-27). None of the remaining planned subgroup analyses could be conducted due to lack of relevant data. ${ }^{11}$

\section{Hospitalisations}

Four trials randomising a total of 9476 HFrEF participants reported on hospitalisations during follow-up. A total of $594 / 4724(12.6 \%)$ sacubitril/valsartan participants were hospitalised during follow-up compared with 756/4752 (15.9\%) control participants. Meta-analysis (RR, 0.79; $95 \%$ CI, 0.72 to $0.87 ; \mathrm{p}=<0.00001$ ) showed evidence of a beneficial effect of sacubitril/valsartan compared with control

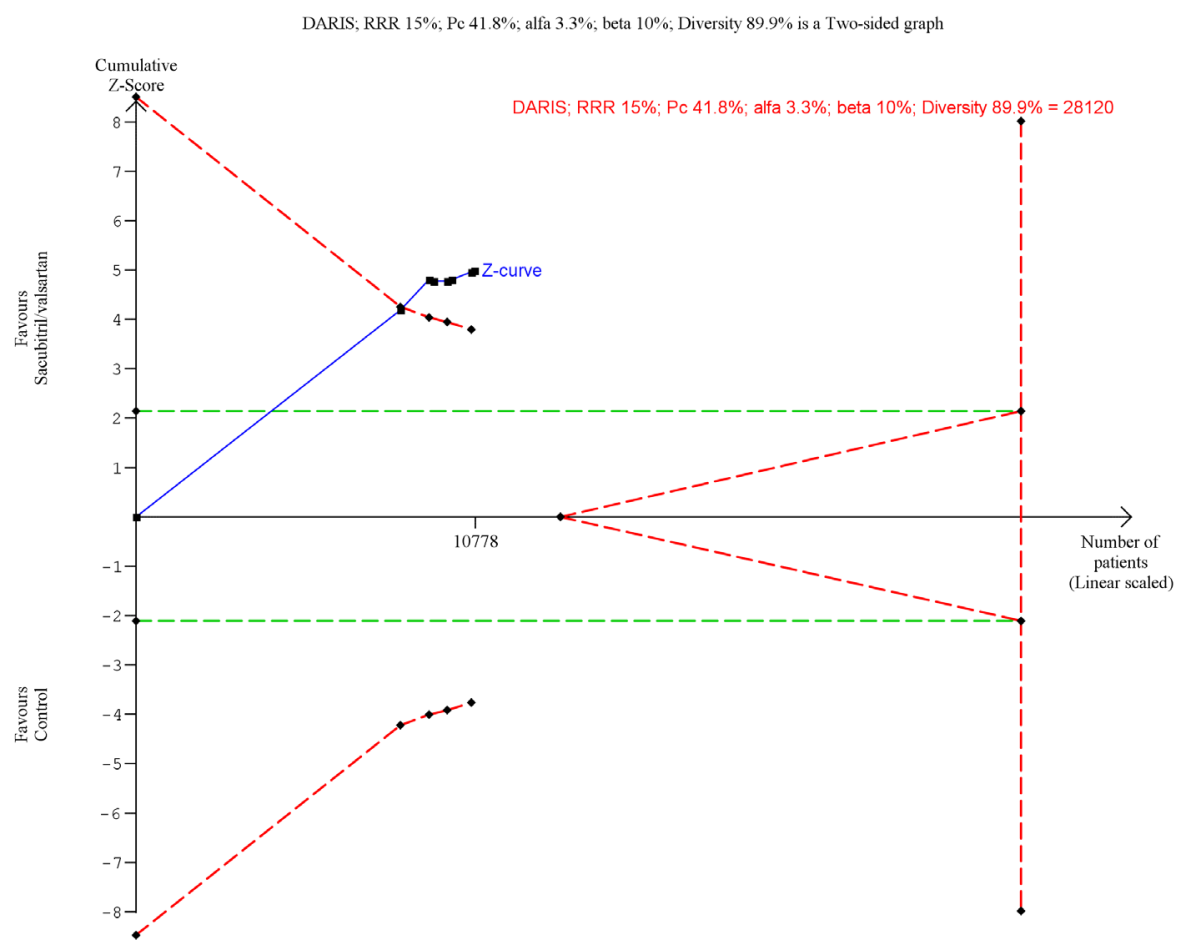

Figure 7 Trial sequential analysis of participants with heart failure with reduced ejection fraction on serious adverse events. 
(online supplemental S28 figure). Neither visual inspection of the forest plot nor tests for statistical heterogeneity $\left(I^{2}=31 \% ; p=0.09\right)$ indicated significant heterogeneity. Trial Sequential Analysis showed that there was enough information to confirm that sacubitril/valsartan compared with control reduced the risk of hospitalisations by $15 \%$ (online supplemental S29 figure). Incomplete outcome data alone did not seem to have the potential to influence the metaanalysis results (online supplemental S30 and S31 figures). Three subgroup analyses showed no evidence of a difference (online supplemental S32-S34 figures). None of the remaining planned subgroup analyses could be conducted due to lack of relevant data. ${ }^{11}$

\section{Exploratory outcomes}

Cardiovascular mortality, ejection fraction, 6-min walking distance and NT-proBNP were analysed as exploratory outcomes. Meta-analyses showed evidence of a beneficial effect of sacubitril/valsartan compared with control when assessing ejection fraction (online supplemental S35 figure), 6-min walking distance (online supplemental S36 figure) and NT-proBNP (online supplemental S37 figure). Only one trial assessed cardiovascular mortality so meta-analysis could not be performed. ${ }^{21}$

\section{Participants with heart failure with preserved ejection fraction}

Primary outcome

All-cause mortality

Three trials randomising a total of $5174 \mathrm{HFpEF}$ participants reported on all-cause mortality. A total of 345/2595 (13.3\%) sacubitril/valsartan participants died compared with 360/2579 (14.0\%) control participants (mean follow-up of 34.1 months). Meta-analysis (RR, 0.95; $95 \%$ CI, 0.83 to 1.09 ; $\mathrm{p}=0.47$ ) showed no evidence of a beneficial effect of adding sacubitril/valsartan compared with control (figure 8). Both visual inspection of the forest plot and test for statistical heterogeneity $\left(\mathrm{I}^{2}=53 \% ; \mathrm{p}=0.12\right)$ indicated moderate heterogeneity. When removing the trial published in China assessing sacubitril/valsartan compared with usual care, with an extreme result, no heterogeneity was observed. Trial Sequential Analysis showed that there was not enough information to confirm or reject that sacubitril/valsartan compared with control reduced the risk of death by $15 \%$ (online supplemental S38 figure). A post-hoc Trial Sequential Analysis showed that there was enough information to confirm that sacubitril/valsartan compared with control did not reduce the risk of death by $20 \%$ (figure 9). Incomplete outcome data alone did not seem to have the potential to influence the meta-analysis results (online supplemental S39 and S40 figures). Test of interaction showed evidence of a difference between (1) trials published in English compared with Chinese $(\mathrm{p}=0.05)$ and (2) different control interventions (valsartan and usual care) $(\mathrm{p}=0.05)$ (online supplemental S41 and S42 figures). None of the remaining planned subgroup analyses could be conducted due to lack of relevant data. ${ }^{11}$

\section{Serious adverse events}

Three trials randomising a total of $5174 \mathrm{HFpEF}$ participants reported on serious adverse events. A total of 1448/2607 (55.5\%) sacubitril/valsartan participants had a serious adverse event compared with 1455/2592 (56.1\%) control participants (mean follow-up of 34.1 months). Meta-analysis (RR, $0.99 ; 95 \%$ CI, 0.94 to $1.04 ; \mathrm{p}=0.63$ ) showed no evidence of a difference between sacubitril/valsartan and control (online supplemental S43 figure). Both visual inspection of the forest plot and test for statistical heterogeneity $\left(I^{2}=64 \% ; p=0.06\right)$ indicated moderate heterogeneity. When removing the trial published in China assessing sacubitril/ valsartan compared with usual care, with an extreme result, no heterogeneity was observed. Trial Sequential Analysis showed that there was enough information to reject that sacubitril/valsartan compared with control reduced the risk of serious adverse events by $15 \%$ (online supplemental S44 figure). Incomplete outcome data alone did not seem to have the potential to influence the meta-analysis results (online supplemental S45 and S46 figures). Test of interaction showed evidence of a difference between (1) trials published in English compared with Chinese $(p=0.04)$ and (2) different control interventions (valsartan and usual care) $(\mathrm{p}=0.04)$ (online supplemental S47 and S48 figures). None of the remaining planned subgroup analyses could be conducted due to lack of relevant data. ${ }^{11}$

\section{Secondary outcomes}

Two trials randomising a total of 5122 HFpEF participants reported on myocardial infarction. Meta-analysis (RR, $0.94 ; 95 \%$ CI, 0.59 to $1.50 ; \mathrm{p}=0.79, \mathrm{I}^{2}=0 \%$ ) showed no evidence of a difference between sacubitril/valsartan and control (online supplemental S49 figure). The same trials reported on non-serious adverse events. Metaanalysis (RR, $0.96 ; 95 \% \mathrm{CI}, 0.85$ to $1.09 ; \mathrm{p}=0.56, \mathrm{I}^{2}=50 \%$ ) showed no evidence of a difference between sacubitril/ valsartan and control (online supplemental S50 figure). Only one trial assessed quality of life using the KCCQ OSS score and found no evidence of a difference. ${ }^{22}$

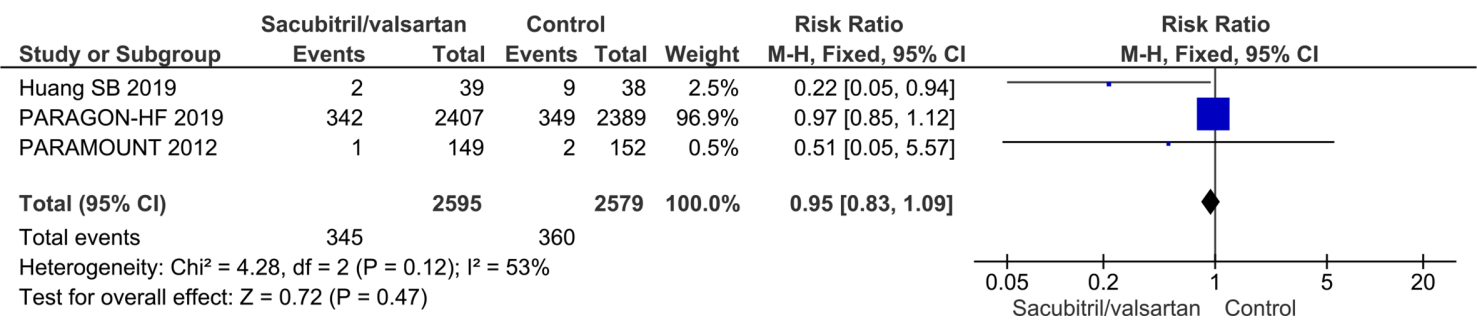

Figure 8 Forest plot of participants with heart failure with preserved ejection fraction on all-cause mortality. 
DARIS; RR 20\%; Pc 14\%; alfa 3.3\%; beta $10 \%$; Diversity $0 \%$ is a Two-sided graph

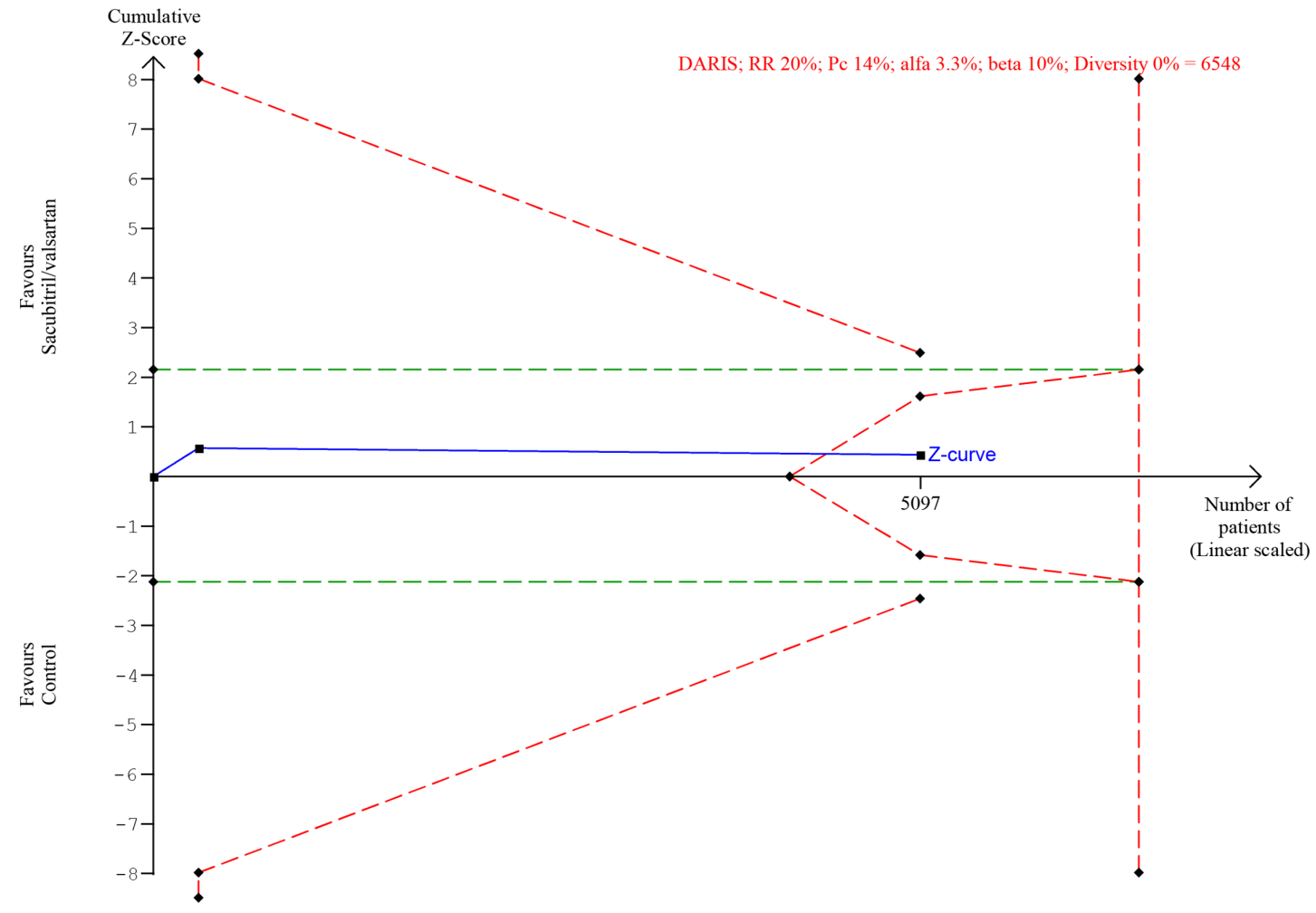

Figure 9 Trial sequential analysis of participants with heart failure with preserved ejection fraction on all-cause mortality.

\section{Exploratory outcomes}

Cardiovascular mortality, ejection fraction, 6-min walking distance and NT-proBNP were analysed as exploratory outcomes. Meta-analysis showed no evidence of a difference when assessing ejection fraction (online supplemental S51 figure). Six-minute walking distance ${ }^{23}$ and NT-proBNP ${ }^{22}$ were only assessed in one trial each so meta-analysis could not be performed. No trials reported cardiovascular mortality.

\section{Summary of findings}

Our main results are presented in the summary of findings tables (tables 3 and 4).

\section{DISCUSSION}

We included a total of 48 trials. HFrEF participants and HFpEF participants were analysed separately due to heterogeneity showing difference in effect between these two types of participants. Twenty-seven trials randomised a total of 12391 HFrEF participants and four trials randomised a total of 5278 HFpEF participants. The remaining 17 trials randomised a total of 1497 participants, did either not report the participants' type of heart failure or included a combination of both HFpEF and HFrEF participants. Nevertheless, these 17 trials did not report any data on our primary outcomes, and very limited data for our secondary outcomes. All trials and outcome results were at high risk of bias. The certainty of the evidence according to GRADE was judged to be moderate to very low (tables 3 and 4 ).

Meta-analyses and Trial Sequential Analyses showed that sacubitril/valsartan compared with control decreases the risk of death, risk of serious adverse events, risk of hospitalisations and NT-proBNP; and seems to increase quality of life using the MLHFQ ejection fraction and 6-min walking distance; and have no effect on myocardial infarction and non-serious adverse events. Current guidelines recommend sacubitril/valsartan as a replacement for ACE-I in HFrEF patients (EF <35\%) who remain symptomatic (NYHA II to IV) despite optimal medical therapy with ACE-I, beta-blocker and mineralocorticoid-receptor antagonist. ${ }^{68}$ Our meta-analyses showed no signs of heterogeneity when including trials regardless of prior treatment with ACE-I, NYHA class and NT-proBNP, that is, our results indicate that sacubitril/valsartan seems to be beneficial in HFrEF patients in general. In addition, we performed a post-hoc subgroup analyses on our primary outcomes, we assessed the difference between trials using guideline recommended inclusion criteria with trials randomising patients with HFrEF irrespective of prior treatment with ACE-I, NYHA class and NT-proBNP. We found no significant subgroup difference (see Primary outcomes). Our results suggest that sacubitril/valsartan might be beneficial for patients with HFrEF in general and not only in the guideline recommended target population. Furthermore, current guidelines highlight that sacubitril/valsartan 
Table 3 Summary of findings table - heart failure with reduced ejection fraction

Sacubitril/valsartan compared with control for heart failure with reduced ejection fraction

Patient or population: heart failure with reduced ejection fraction

Intervention: sacubitril/valsartan

Comparison: control

\begin{tabular}{|c|c|c|c|c|c|}
\hline \multirow[b]{2}{*}{ Outcomes } & \multirow{2}{*}{$\begin{array}{l}\text { No of participants } \\
\text { (studies) } \\
\text { follow-up }\end{array}$} & \multirow{2}{*}{$\begin{array}{l}\text { Certainty of } \\
\text { the evidence } \\
\text { (GRADE) }\end{array}$} & \multirow[b]{2}{*}{$\begin{array}{l}\text { Relative effect } \\
(95 \% \mathrm{CI})\end{array}$} & \multicolumn{2}{|c|}{ Anticipated absolute effects } \\
\hline & & & & Risk with control & $\begin{array}{l}\text { Risk difference with } \\
\text { ARNI }\end{array}$ \\
\hline $\begin{array}{l}\text { Serious adverse events follow- } \\
\text { up: mean } 23 \text { months }\end{array}$ & $\begin{array}{l}10794 \\
\text { (seven RCTs) }\end{array}$ & $\begin{array}{l}\oplus \bigoplus \bigoplus \bigcirc \\
\text { MODERATE* }\end{array}$ & $\begin{array}{l}\text { RR } 0.89 \\
(0.86 \text { to } 0.94)\end{array}$ & 418 per 1.000 & $\begin{array}{l}\mathbf{4 6} \text { fewer per } 1.000 \\
\text { (59 fewer to } 25 \text { fewer) }\end{array}$ \\
\hline $\begin{array}{l}\text { Quality of life assessed with: } \\
\text { MLHFQ follow-up: mean } 2 \\
\text { months }\end{array}$ & $\begin{array}{l}232 \\
\text { (two RCTs) }\end{array}$ & $\begin{array}{l}\oplus \bigcirc \bigcirc \bigcirc \\
\text { VERY LOW§ণ }\end{array}$ & - & & $\begin{array}{l}\text { MD } 5.19 \text { score lower } \\
\text { (8.37 lower to } 2.01 \text { lower) }\end{array}$ \\
\hline $\begin{array}{l}\text { Non-serious adverse events } \\
\text { follow-up: mean } 23\end{array}$ & $\begin{array}{l}10401 \\
\text { (nine RCTs) }\end{array}$ & $\begin{array}{l}\oplus \oplus \bigcirc \bigcirc \\
\mathrm{LOW}^{*} \dagger\end{array}$ & $\begin{array}{l}\text { RR } 0.95 \\
\text { (0.84 to } 1.08)\end{array}$ & 547 per 1.000 & $\begin{array}{l}27 \text { fewer per } 1.000 \\
\text { (88 fewer to } 44 \text { more) }\end{array}$ \\
\hline
\end{tabular}

The risk in the intervention group (and its $95 \% \mathrm{Cl}$ ) is based on the assumed risk in the comparison group and the relative effect of the intervention (and its $95 \% \mathrm{Cl}$ ).

GRADE, Working Group grades of evidence.

High certainty: We are very confident that the true effect lies close to that of the estimate of the effect.

Moderate certainty: We are moderately confident in the effect estimate. The true effect is likely to be close to the estimate of the effect, but there is a possibility that it is substantially different.

Low certainty: Our confidence in the effect estimate is limited. The true effect may be substantially different from the estimate of the effect.

Very low certainty: We have very little confidence in the effect estimate. The true effect is likely to be substantially different

from the estimate of effect.

*Downgraded 1 for risk of bias, due to industry funding.

†Downgraded 1 for risk of inconsistency due to moderate heterogeneity.

‡Downgraded 1 for imprecision due to Trial Sequential Analysis showing that there was not enough information to confirm or reject a RRR of $15 \%$. Moreover, the meta-analysis showed wide $\mathrm{Cl}$.

§Downgraded 2 for risk of bias.

ПDowngraded 2 for risk of inconsistency due to substantial heterogeneity.

$\mathrm{RR}$, risk ratio; $\mathrm{MD}$, mean difference; $\mathrm{ARNI}$, angiotensin receptor blocker neprilysin inhibitor; RCTs, randomised controlled

trials; MLHFQ, Minnesota Living with Heart Failure Questionnaire; MD, mean difference.

is associated with an increased risk of hypotension and angioedema. Our results showed no evidence of a difference between sacubitril/valsartan and control when assessing risk of hypotension and angioedema.

In HFpEF participants, meta-analysis and Trial Sequential Analysis showed no evidence of a difference between sacubitril/valsartan and control when assessing all-cause mortality, serious adverse events, myocardial infarction, non-serious adverse events, quality of life and ejection fraction. Not enough data was available for the remaining outcomes.

Our review has several strengths. We followed our protocol, which was registered and published prior to the systematic literature search. ${ }^{11}$ Data were extracted by two authors in order to minimise the risk of inaccurate data extraction. This systematic review considered both risks of random errors and risks of systematic errors. Bias was assessed according to Cochrane ${ }^{13}$ and Lundh. ${ }^{14}$ We used GRADE to assess the certainty of the evidence, ${ }^{24} 25$ Trial Sequential Analysis to assess the risks of random errors, (online supplemental S3 ref) the eight-step assessment suggested by Jakobsen et al to assess if the thresholds for significance were crossed, ${ }^{17}$ subgroup analyses to assess possibly heterogeneity and sensitivity analyses to test the potential impact of incomplete outcome data bias. ${ }^{17}$ We included data from both unpublished and published trials.

Our review also has several limitations. The majority of our participants came from two trials, ${ }^{18} 19$ which held the largest weight in our meta-analysis. However, the heterogeneity of the trials in our meta-analysis was judged very low, both by test of heterogeneity $(\mathrm{p}=0.84)$, and by visual inspection. In addition, the 
Table 4 Summary of findings table - heart failure with preserved ejection fraction

Sacubitril/valsartan compared with control for heart failure with preserved ejection fraction

Patient or population: heart failure with preserved ejection fraction

Intervention: sacubitril/valsartan

Comparison: control

\begin{tabular}{|c|c|c|c|c|c|}
\hline \multirow[b]{2}{*}{ Outcomes } & \multirow{2}{*}{$\begin{array}{l}\text { No of participants } \\
\text { (studies) } \\
\text { follow-up }\end{array}$} & \multirow{2}{*}{$\begin{array}{l}\text { Certainty of the } \\
\text { evidence } \\
\text { (GRADE) }\end{array}$} & \multirow[b]{2}{*}{$\begin{array}{l}\text { Relative effect } \\
(95 \% \mathrm{Cl})\end{array}$} & \multicolumn{2}{|c|}{ Anticipated absolute effects } \\
\hline & & & & $\begin{array}{l}\text { Risk with } \\
\text { control }\end{array}$ & $\begin{array}{l}\text { Risk difference with } \\
\text { ARNI }\end{array}$ \\
\hline $\begin{array}{l}\text { Serious adverse events follow-up: mean } \\
34 \text { months }\end{array}$ & $\begin{array}{l}5174 \\
\text { (three RCTs) }\end{array}$ & $\begin{array}{l}\oplus \oplus \bigcirc \bigcirc \\
\mathrm{LOW}^{*} \dagger\end{array}$ & $\begin{array}{l}\text { RR } 0.99 \\
(0.94 \text { to } 1.04)\end{array}$ & 564 per 1.000 & $\begin{array}{l}\mathbf{6} \text { fewer per } 1.000 \\
\text { (34 fewer to } 23 \text { more) }\end{array}$ \\
\hline $\begin{array}{l}\text { Non-serious adverse events follow-up: } \\
\text { mean } 34 \text { months }\end{array}$ & $\begin{array}{l}5122 \\
\text { (two RCTs) }\end{array}$ & $\begin{array}{l}\oplus \oplus \bigcirc \bigcirc \\
\mathrm{LOW}^{*}+\end{array}$ & $\begin{array}{l}\text { RR } 0.96 \\
(0.85 \text { to } 1.09)\end{array}$ & 934 per 1.000 & $\begin{array}{l}37 \text { fewer per } 1.000 \\
\text { (140 fewer to } 84 \text { more) }\end{array}$ \\
\hline
\end{tabular}

The risk in the intervention group (and its $95 \% \mathrm{Cl}$ ) is based on the assumed risk in the comparison group and the relative effect of the intervention (and its $95 \% \mathrm{Cl}$ ).

GRADE, Working Group grades of evidence.

High certainty: We are very confident that the true effect lies close to that of the estimate of the effect.

Moderate certainty: We are moderately confident in the effect estimate. The true effect is likely to be close to the estimate of the effect, but there is a possibility that it is substantially different.

Low certainty: Our confidence in the effect estimate is limited. The true effect may be substantially different from the estimate of the effect.

Very low certainty: We have very little confidence in the effect estimate. The true effect is likely to be substantially different from the estimate of

effect.

*Downgraded 1 for serious risk of bias.

†Downgraded 1 for inconsistency due to moderate heterogeneity.

fDowngraded 1 for imprecision due to Trial Sequential Analysis showing that there was not enough information to confirm or reject a RRR of $15 \%$.

Moreover, the meta-analysis showed wide $\mathrm{Cl}$.

$\mathrm{RR}$, risk ratio; $\mathrm{ARNI}$, angiotensin receptor blocker neprilysin inhibitor; RCTs, randomised controlled trials.

point estimates of the smaller trials is mostly centred around the RR of the meta-analysis results, indicating that the results of the larger trials are reproducible. All included trials had high risk of bias, which might bias our review results. ${ }^{14}$ All nine English published trials were sponsored by Novartis, which currently produces the only licensed sacubitril/valsartan. This might introduce high risk of bias as study-sponsored studies tend to show more favourable efficacy results and conclusions than trials receiving sponsorship by other sources. ${ }^{14}$ These limitations should be considered when interpreting the results. There were differences in the choice of control intervention for trials including HFrEF participants. The majority of trials with HFrEF participants used enalapril as control intervention with a target dose of $10 \mathrm{mg}$ twice daily, below the guideline recommended dose of $20 \mathrm{mg}$. However, the dose is higher than in the trials that lay the basis for recommending enalapril in the first place. In our meta-analysis of trials with HFpEF participants, all trials used valsartan as control except one small trial. However, valsartan is not recommended in guidelines for HFpEF patients, due to their failure to show benefit in large randomised trials. ${ }^{2627}$ The choice of control interventions has been an issue of debate and our present results should be interpreted accordingly. ${ }^{28}{ }^{29}$ Subgroup analyses assessing the potential difference between control interventions, showed no significant subgroup difference.

We identified 12 ongoing trials. Characteristics of the ongoing trials are summarised in (online supplemental S2 table).

\section{CONCLUSIONS}

Sacubitril/valsartan compared with either ACE-I or ARB seems to have a beneficial effect in patients with heart failure with reduced ejection fraction. Our results indicate that sacubitril/valsartan might be beneficial in a wider population of patients with heart failure than the guideline recommended target population. Sacubitril/ valsartan does not seem to show evidence of a difference compared with valsartan in patients with heart failure with preserved ejection fraction.

\section{Author affiliations}

${ }^{1}$ Department of Internal Medicine - Cardiology Section, Holbaek Hospital, Holbaek, Denmark

${ }^{2}$ Institute of Regional Health Research, University of Southern Denmark, Odense, Denmark

${ }^{3}$ Beijing Children's Hospital, Capital Medical University, Beijing, China ${ }^{4}$ Centre for Individualized Medicine in Arterial Diseases (CIMA), Odense University Hospital, University of Southern Denmark, Odense, Denmark

${ }^{5}$ Copenhagen Trial Unit, Centre for Clinical Intervention Research, Department 7812, Rigshospitalet, Copenhagen University Hospital, Copenhagen, Denmark 
Acknowledgements Department of Internal Medicine - Cardiology Section, Holbæk Hospital, Denmark, and the Institute of Regional Health Research, University of Southern Denmark, Odense, Denmark, paid the salary for all authors during the writing of the review.

Contributors EEN conceived the systematic review, conducted the literature search, data extraction, data analysis, data interpretation and wrote the article. JF conducted the literature search, data extraction, aided in data interpretation and amended the article. F-LB conducted the literature search, data extraction and amended the article. MHO, IR, and FS-H helped conceive the systematic review, provided invaluable comments and amended the article. JCJ conceived the systematic review, aided in data interpretation and amended the article.

Funding The authors have not declared a specific grant for this research from any funding agency in the public, commercial or not-for-profit sectors.

Disclaimer No ethics approval was obtained, as all data is anonymised and all data used is obtained from clinical trials in which informed consent has already been obtained by trial investigators.

Competing interests None declared.

Patient consent for publication Not required.

Provenance and peer review Not commissioned; externally peer reviewed.

Data availability statement All data relevant to the study are included in the article or uploaded as supplementary information.

Open access This is an open access article distributed in accordance with the Creative Commons Attribution Non Commercial (CC BY-NC 4.0) license, which permits others to distribute, remix, adapt, build upon this work non-commercially, and license their derivative works on different terms, provided the original work is properly cited, appropriate credit is given, any changes made indicated, and the use is non-commercial. See: http://creativecommons.org/licenses/by-nc/4.0/.

ORCID iD

Emil Eik Nielsen http://orcid.org/0000-0003-1108-9533

\section{REFERENCES}

1 Bui AL, Horwich TB, Fonarow GC. Epidemiology and risk profile of heart failure. Nat Rev Cardiol 2011;8:30-41.

2 Ziaeian B, Fonarow GC. Epidemiology and aetiology of heart failure. Nat Rev Cardiol 2016;13:368-78.

3 WRITING COMMITTEE MEMBERS, Yancy CW, Jessup M, et al. 2013 ACCF/AHA guideline for the management of heart failure: a report of the American College of cardiology Foundation/American heart association Task force on practice guidelines. Circulation 2013;128:e240-327.

4 Maggioni AP. Epidemiology of heart failure in Europe. Heart Fail Clin 2015;11:625-35.

5 McMurray JJ, Stewart S. Epidemiology, aetiology, and prognosis of heart failure. Heart 2000;83:596-602.

6 Ponikowski P, Voors AA, Anker SD, et al. 2016 ESC guidelines for the diagnosis and treatment of acute and chronic heart failure: the task force for the diagnosis and treatment of acute and chronic hear failure of the European Society of cardiology (ESC). developed with the special contribution of the heart failure association (HFA) of the ESC. Eur J Heart Fail 2016;18:891-975.

7 Jhund PS, McMurray JJV. The neprilysin pathway in heart failure: a review and guide on the use of sacubitril/valsartan. Heart 2016;102:1342-7.

8 Yancy CW, Jessup M, Bozkurt B, et al. 2017 ACC/AHA/HFSA Focused Update of the 2013 ACCF/AHA Guideline for the Management of Heart Failure: A Report of the American College of Cardiology/American Heart Association Task Force on Clinical Practice Guidelines and the Heart Failure Society of America. $J$ Card Fail 2017;23:628-51.

9 Moher D, Shamseer L, Clarke M, Ghersi D, et al. Preferred reporting items for systematic review and meta-analysis protocols (PRISMA-P) 2015 statement. Syst Rev 2015;4:1.

10 Shamseer L, Moher D, Clarke M, et al. Preferred reporting items for systematic review and meta-analysis protocols (PRISMA-P) 2015: elaboration and explanation. BMJ 2015;350:g7647.

11 Nielsen EE, Feinberg J, Raymond I, et al. The effects of adding angiotensin receptor neprilysin inhibitors to usual care in patients with heart failure: a protocol for a systematic review of randomised clinical trials with meta-analysis and trial sequential analysis. Syst Rev 2019;8:251.

12 Review Manager [program]. 5.3 version 2014.
13 Higgins JPT GS. Cochrane Handbook for systematic reviews of interventions version 5.1.0, 2011. www.cochrane-handbook.org

14 Lundh A, Lexchin J, Mintzes B, et al. Industry sponsorship and research outcome. Cochrane Database Syst Rev 2017;2:Mr000033.

15 DerSimonian R, Laird N. Meta-analysis in clinical trials revisited. Contemp Clin Trials 2015;45:139-45.

16 Demets DL. Methods for combining randomized clinical trials: strengths and limitations. Stat Med 1987;6:341-8.

17 Jakobsen JC, Wetterslev J, Winkel P, et al. Thresholds for statistical and clinical significance in systematic reviews with meta-analytic methods. BMC Med Res Methodol 2014;14:120.

18 Solomon SD, McMurray JJV, Anand IS, et al. Angiotensin-Neprilysin inhibition in heart failure with preserved ejection fraction. $N$ Engl $J$ Med 2019;381:1609-20.

19 McMurray JJV, Packer M, Desai AS, et al. Angiotensin-Neprilysin inhibition versus enalapril in heart failure. $N$ Engl $J$ Med 2014;371:993-1004.

20 Lewis EF, Claggett BL, McMurray JJV, et al. Health-Related quality of life outcomes in PARADIGM-HF. Circulation 2017;10.

21 McMurray JJV, Packer M, Desai AS, et al. Angiotensin-neprilysin inhibition versus enalapril in heart failure. N Engl J Med 2014;371:993-1004.

22 Solomon SD, Zile M, Pieske B, et al. The angiotensin receptor neprilysin inhibitor LCZ696 in heart failure with preserved ejection fraction: a phase 2 double-blind randomised controlled trial. Lancet 2012;380:1387-95.

23 Han Z. nuoxintuozhiliao zuo xinshi she xie fenshu baoliu de xinshuai linchuang liaoxiao guancha [Clinical observation of noxin injection in the treatment of heart failure with left ventricular ejection fraction] yangsheng baojian zhinan [Health Guide] 2019;29:140.

24 Guyatt GH, Oxman AD, Vist GE, et al. GRADE: an emerging consensus on rating quality of evidence and strength of recommendations. BMJ 2008;336:924-6.

25 Guyatt GH, Oxman AD, Schünemann HJ, et al. GRADE guidelines: a new series of articles in the Journal of Clinical Epidemiology. J Clin Epidemiol 2011;64:380-2.

26 Massie BM, Carson PE, McMurray JJ, et al. Irbesartan in patients with heart failure and preserved ejection fraction. $N$ Engl $J$ Med 2008;359:2456-67.

27 Yusuf S, Pfeffer MA, Swedberg K, et al. Effects of candesartan in patients with chronic heart failure and preserved leftventricular ejection fraction: the CHARM-Preserved trial. Lancet 2003;362:777-81.

28 Shapiro MA. Paradigms and PARAGON-HF. JACC Heart Fail 2018;6:86.

29 Bernardez-Pereira S, Ramires FJA, de Melo RFT, et al. Was the enalapril dose too low in the PARADIGM-HF trial? Cardiol Rev 2018;26:196-200.

30 Owens RL, Birkeland K, Heywood JT, et al. Sleep outcomes from AWAKE-HF, a randomized clinical trial with open-label extension of sacubitril/valsartan versus enalapril in patients with heart failure with reduced ejection fraction. J Am Coll Cardiol 2019;73:849.

31 pharmaceuticals N. A randomized, double-blind, controlled, crossover study to evaluate the sodium excretion of LCZ696 in patients with stable heart failure, in patients with hypertension, and in healthy volunteers. Identifier CLCZ696B2223. Novartis Pharmaceuticals Clinical registry, 2013.

32 Desai AS, Solomon SD, Shah AM, et al. Effect of SacubitrilValsartan vs enalapril on aortic stiffness in patients with heart failure and reduced ejection fraction: a randomized clinical trial. JAMA 2019:1077-10

33 Pharmaceuticals $\mathrm{N}$. randOmized stUdy using acceleromeTry to compare Sacubitril/valsarTan and enalapril in patients with heart failure 2016. Available: https://clinicaltrials.gov/ct2/show/ nct02900378

34 Velazquez EJ, Morrow DA, DeVore AD, et al. Angiotensin-Neprilysin inhibition in acute decompensated heart failure. $N$ Engl $J$ Med 2019;380:539-48.

35 Kang D-H, Park S-J, Shin S-H, et al. Angiotensin receptor neprilysin inhibitor for functional mitral regurgitation. Circulation 2019;139:1354-65.

36 Chai DJ, Cheng K, Tu X, et al. shakubaquxieshatan zhiliao wanguxingxinlishuaijie de liaoxiao yu anquanxingguancha [The efficacy and safety of entresto in treatment of patients with refractory heart failure ]. xindian yu xunhuan 2019;38:301-3.

37 Chen CW. shakubaquxieshatan zhiliao manxing xinlishuaijie de xiaoguo tantao [Effect of Sacubitril Valsartan on the Treatment of Chronic Heart Failure]. zhongxiyijiehe dianzi zazhi 2019;22:40-1.

38 Chen L, Lu W, Wu Y, et al. shakubaquxieshatan duishexie fenshu jiangdi de xinlishuaijie ji huanzhe shenghua zhibiao he zuo xinshi jiegou de ganyu zuoyong [ Effects of Saeubitril / Valsartan on 
biochemical indicators and on left ventricular structure in NYHA Vheart failure with reduced ejection fraction patients]. zhonghua laonianyixue zazhi 2019;38.

39 Dai WL, Wu X, Wang S, et al. shakubaquxieshatan zhiliao manxing chongxue xing xinlishuaijie huanzhe de linchuang yanjiu [Clinical research on sacubitril/valsartan treating patients with chronic congestive heart failure]. zhongguo yiyao 2019;9:1297-301.

40 Dong L, Tian Y, Liu S, et al. shakubaquxieshatan napiandui manxing xinlishuaijie huanzhe de liaoxiao ji dui shenjing neifenmi jisu yingxiang [Efficacy of sacubitril/valsartan sodium tablets in treatment of chronic heart failure and the effect on neuroendocrine hormone activity ]. zhongguo yiyao 2019;14:655-8.

41 Fan JF, Fang Y, Zheng C. shakubaquxieshatanna zhiliao manxing xinlishuaijie huanzhe de linchuang liaoxiao fenxi [Clinical efficacy of sacubitril valsartan in the treatment of chronic heart failure ]. zhongguo linchuang yaolixue yu zhiliaoxue 2019;24:810-4.

42 Fan TT, He F, Wang X. shakubaquxieshatanyuxieshatan zhiliao manxing xinlishuaijie de zaoqi linchuang liaoxiao bijiao [Comparison of early clinical efficacy of sacubitril/ valsartan(LCZ696) and valsartan in treatment of chronic heart failure ]. anhui yixue 2019;40:618-21.

43 Fan ZL, Liu S, Xie G, et al. shakubaquxieshatan dui chongxue xing xinlishuaijie huanzhe xueguan neipi sunshang yu xinshi chongsu zhuangtai de yingxiangyanjiu [Study on the Influence of Sacubitril Valsartan for the Vascular Endothelial Injury and Ventricular Remodeling State of Patients with Congestive Heart-failure]. zhongguo yixue chuangxin 2019;16:51-4.

44 Gao Y, Luan B, Gao Y, et al. shakubaquxieshatan zhiliao manxing xinlishuaijie de linchuang guancha [Clinical observation of Sacrubitril Nalsartan in the treatment of chronic heart failure]. zhongguo xun zheng xinxueguan yixue zazhi 2019;11:595-7.

45 Hao QM, Cheng J, Xue Y, et al. bijiao shakubaquxieshatan yuxieshatandui manxing xinshuai huanzhe xinsheng de yingxiang [Comparison of the Effects of Sacubitril/valsartan and Valsartan on Heart and Kidney Function in Patients with Chronic Heart Failure ]. xiandai shengwuyixue jinzhan 2019;4:2691-4.

46 Huang $\mathrm{SB}$, Chen $\mathrm{H}$, Zhou $\mathrm{H}$. shakubaquxieshatan zhiliao xinzangshexiefenshuxiajiang de xinlishuaijiehuanzhe liaoxiaoguancha [Curative Effect Observation of Sacubitril Valsartan in Patients with Heart Failure with Decreased Cardiac Ejection Fraction ]. Neike 2019;14:337-8.

47 ZF K, Liang Y, Zhang Z, et al. shakubaquxieshatan zhiliao manxing she xie fenshu jiangdi xinlishuaijie li linchuang guancha [Clinical observation of sacubitril-valsartan in chronic heart failure with reduced ejection fraction]. guangdong yikedaxue xuebao 2019;37:335-8.

48 GX L. shakubaquxieshatan nayubeinapuli zhiliao manxing xinshuai de linchuang xiaoguo pingjia [Clinical evaluation of the treatment of chronic heart failure with Sacubitril Valsartan sodium and benazepril]. ren jiankang 2019;19:125.

49 Li J, Cao J, Liu W, et al. shakubaquxieshatan zhiliao laonianren kuozhang xing xinji bing zhi manxing xinlishuaijie de liaoxiao guancha [Efficacy of Sacubitril / Valsartan in the treatment of chronic heart failure in elderly patients with dilated cardiomyopathy ]. zhonghua laonianyixue zazhi 2019;38.

$50 \mathrm{Li} \mathrm{J}$, Cao J, Danzeng L, et al. shakubaquxieshatan napian zhiliao gaoyuan diqu gaoxueya manxing xinlishuaijie huanzhe de linchuang xiaoguo [Clinical effect of sacubitril valsartan sodium tablets on hypertensive patients with chronic heart failure in plateau area] zhongguo yiyao 2019;14:321-4.

51 Liang HB. shakubaquxieshatan yu pei duo pu li zhiliao she xie fenshu jiangdi de xinlishuaijie de linchuang liaoxiao bijiao [Comparison of the clinical efficacy in the treatment of heart failure with reduced ejection fraction by of sacubitril/valsartan and perindopril ]. guangxi yikedaxue 2019

52 Liu DN, Li X, Ma J, et al. shakubaquxieshatanna zhiliao she xie fenshu jianshao manxing xinlishuaijie de yanjiu [Therapeutic Effects of Sacubitril/ Valsrtan in Heart Failure Patients and Reduced Ejection Fraction ]. ningxia yixue zazhi 2019:4:1-4.

53 Liu YH, Li F, Wang J, et al. shakubaquxieshatan zhiliao manxing xinlishuaijie [Observation on the Therapeutic Effect of Sacubitril Valsartan on Chronic Heart Failure]. changchun zhongyi yao daxue xuebao 2019;35:457-60.

54 SH P, Guan Y, Yang Z, et al. shakubaquduanshatan zhiliao zuo xinshi she xie fenshu jiangdi xinlishuaijie huanzhe de linchuang liaoxiao guancha [The efficiency of Sacubitril/Valsartan therapy in patients with heart failure with reduced ejection fraction]. zhongguo yanjiu 2019;17.

55 Shen JH. shakubaquxieshatan zhiliao manxing xinlishuaijie de liaoxiao ji anquanxing yanjiu [Efficacy and safety of saponin and valsartan in the treatment of chronic heart failure]. zhongguo baojian yingyang 2019;29:266.
56 Song Z, Peng J, Liu Z, et al. shakubaquxieshatan lianhe qumeitaqin zhiliao manxing xinlishuaijie de linchuang guancha [Clinical efficacy of combined sacubitril-valsartan and trimetazidine in chronic heart failure ]. guangdong yikedaxue xuebao 2019;37:331-4.

57 Sun X, Jia Y. shakubaquxieshatanna zhiliao manxing xinlishuaijie de linchuang liaoxiao guancha [Clinical observation of the efficacy of sirubatra and valsartan in the treatment of chronic heart failure]. shijie zuixin yixue xinxi wenzhai 2019;19:125.

58 Sun XN, Qu F. nuoxintuodui manxing xin gongneng bu quan huanzhe shenghuozhiliang de yingxiang [Effect of Entresto on quality of life in patients with chronic heart failure ]. jiankang bi dou 2018:17:20-1.

59 Tang J. shakubaquxieshatan lianhe bisuo luo er zhiliao manxing xinlishuaijie de linchuang xiaoguo guancha [Clinical observation of the treatment of chronic heart failure with saponin and bisoprolol ]. linchuang heli yongyao zazhi 2018;11:39-40.

60 Wang QD, Lai M. shakubaquxiesh tan duijixingduan taigao xing qian bi xinjigengsi bing xinlishuaijie huanzhe xin yingxiang [Effect of Sacubitril Valsartan on cardiac function in patients with acute ST- segment elevation myocardial infarction of the anterior wall complicated with heart failure ]. guangzhou yikedaxue xuebao 2019;47:92-5.

61 Wei ZX, Dongo L, Yuan Z, et al. shakubaquxieshatan zhiliao zuoxinjibing xiangguanxing feidongmaigaoya de linchuangyanjiu [Clinical trial of sacubitril/valsartan in the treatment of Pulmonary hypertension $(\mathrm{PH})$ due to left heart disease (LHD)]. zhongguo linchuang yaolixue yu zhiliaoxue 2019;24:57-62.

$62 \mathrm{MM} \mathrm{W}$. shakubaquxieshatan duishexie fenshu jiangdi de xinlishuaijie huanzhe xin yingxiang [Effect of Sacubitril/valsartan on heart function in patients with heart failure reducedd ejection fraction]. hebei yikedaxue 2018.

63 Yang J. shakubaquxieshatan nayubeinapuli zhiliao manxing xinshuai de liaoxiao guancha [Therapeutic effect of saponin and valsartan on chronic heart failure]. mu ying shijie 2019;13:134-6.

64 Yang RC, Wang S. shakubaquxieshatan zhiliao tangniaobing xinji bing xin gongneng bu quan de linchuang liaoxiao guancha[Observation on Clinical Therapeutic Effect of Sacubitril uba and Valsartan on Cardiac Dysfunction in Patients with Diabetic Cardiomyopathy ]. zhongguo heli yongyao tansuo 2019;16:121-3.

65 Yao LN. shakubaquxieshatan zhiliao gaoling she xie fenshu jiangdi xinlishuaijie [Sacubitril Valsartan in the treatment of advanced ejection fraction reduces heart failure]. zhongxiyijiehe dianzi zazhi 2019;7:5-6.

$66 \mathrm{Yu} \mathrm{H}$, Zhao T, Liu K. shakubaquxieshatan napian zhiliao laonian manxing xinlishuaijie de xiaoguo [Effect of Sacubitril Valsartan Tablets on Elderly Patients with Chronic Heart Failure]. zhongguo laonianxue zazhi 2019;39:3620-2.

67 ZL Y. shakubaquxieshatan zhiliao wanguxingxinlishuaijie de xiaoguoguancha [Effect of Shakuba Qusarsar on the Treatment of Refractory Heart Failure]. haixia yaoxue 2018;30:194-5.

68 Zhang $\mathrm{H}$. shakubaquxieshatan yuyinapuli dui quexue xing xinji binghuan zhe xueliu jie dao de xieguankuozhang gongneng ji jingdongmai neizhong mo houdu de yingxiang [The effects of sacubitril/valsartan versus enalapril on flow-mediated dilation and carotid intima-media thickness in patients with heart failure and obstructive coronary artery disease] 2018.

69 Zhang JW, Xie Z, Wu F, et al. sha ku ba qu xie sha tan na pian nuo xin tuo dui manxing xinlishuaijie huanzhe liaoxiao ji shuiping de [The effect of Sacubitril Valsartan Sodium Tablets (Entresto) on the curative effect and the influence of BNP of in patients with chronic heart failure]. jilin yixue 2019;40:1430-3.

70 Zhang XJ, Huang W, Xu Y. shakubaquxieshatanhe yansuan beinapuli pian duixin li shuaijie huanzhe xinshi chongsu yanzheng yinzi de yingxiang [Clinical study of the effects of entresto and lotensin on ventricular remodeling and inflammatory factors in patients with heart failure ]. shiyong yixue zazhi 2019;35:795-9.

71 Zhang Y, Yang G, Li D, et al. shakubaquxieshatan zhiliao manxing xinlishuaijie fei dongmai gaoya de liaoxiao fenxi [Efficacy of sacubitril/valsartan on pulmonary hypertension associated with left heart failure with reduced ejection fraction]. yiyao luntan zazhi 2019:40:5-8

72 Zhang YZ, Zhao C, Cao Q, et al. shakubaquxieshatan nayubeinapuli zhiliao manxing xinshuai de liaoxiao guancha [Therapeutic effect of saponin and valsartan on chronic heart failure]. shijie zuixin yixue xinxi wenzhai 2019;19:128-9.

73 Zhao YQ, Liu H, Yang Y, et al. shakubaquxieshatan lianhe andiantong zhiliao hebing zhen fa xing fang chan de laonian xing xinlishuaijie de liaoxiao guancha [Therapeutic effects of sacubitril valsartan combined with amiodarone on senile heart failure complicated by paroxysmal atrial fibrillation ]. hebei yiyao 2019;41:404-6. 